\title{
Warriors without armors: Human Rights violations against healthcare workers in the times of COVID-19
}

\author{
Namrata Roy ${ }^{1}$, Mohammed Ateeq Ur Rahman ${ }^{2}$, Zareena Fathah ${ }^{3}$, Nour Ammar ${ }^{4}$, Aizaz \\ Ali $^{5}$, Walaa A. Kamel ${ }^{6,7}$, Nohora Cristina Ayala-Serrano ${ }^{8}$, Sadeq Quraishi ${ }^{9}$, Ebrahim \\ Barkoudah $^{10}$, Russell Franco D'Souza ${ }^{11,12}$, Ranjit Sah ${ }^{13}$, Mary Matthew ${ }^{14}$ \\ ${ }^{1}$ SRM University, SRM Nagar, Kattankulathur - 603 203, Chengalpattu District, Tamil Nadu, \\ India. \\ ${ }^{2}$ Karnatak University, Dharwad, Hubli, Karnataka, India. \\ ${ }^{3}$ Kings College London, London, United Kingdom. \\ ${ }^{4}$ Faculty of Dentistry, Alexandria University, Alexandria, Egypt. \\ ${ }^{5}$ Shifa International Hospital, Islamabad, Pakistan. \\ ${ }^{6}$ Neurology Department, Ibn-Sina Hospital, Kuwait. \\ ${ }^{7}$ Neurology department, Faculty of Medicine, Beni-Suef University, Egypt. \\ ${ }^{8}$ CEMIC Mental Health Clinic, Cabrero Calle Real \#42-62, Cartagena, Colombia 13003. \\ ${ }^{9}$ Department of Anesthesiology and Perioperative Medicine - Tufts Medical Center, Tufts \\ University School of Medicine, 800 Washington St, Ziskind 6038, Boston, MA 02111, USA. \\ ${ }^{10}$ Harvard School of Public Health Boston, Massachusetts, USA. \\ ${ }^{11}$ Head, Asia Pacific Division, Director of Education, International Program, UNESCO Chair in \\ Bioethics, University of Haifa, Directorate of The Asia Pacific Division and Education \\ Department, Melbourne Australia. \\ ${ }^{12}$ Executive Director and Dean, Professor of Organizational Psychological Medicine, \\ International Institute of Organisational Psychological Medicine, AUSTRALIA: USA: UK. \\ ${ }^{13}$ Tribhuvan University Teaching Hospital, Institute of Medicine, Kathmandu, Nepal. \\ ${ }^{14}$ Department of Pathology, Kasturba Medical College, Manipal Academy of Higher Education, \\ Karnataka, India. \\ Corresponding Author: Namrata Roy \\ E-mail: drnamrata.2017@gmail.com
}

\section{Introduction}

The United Nations defines Human rights as "rights inherent to all human beings, regardless of race, sex, nationality, ethnicity, language, religion, or any other status [1]. Human rights include the right to life and liberty, freedom from slavery and torture, freedom of opinion and expression, the right to work and education, and many more [2]. Everyone is entitled to these rights, without discrimination." On the 10th of December, 1948, in Palais de Chaillot, Paris, the Universal Declaration of Human Rights (UDHR) was adopted by the United Nations [3]. Even though it is not a treaty nor is it legally binding, it has helped shape the concept of universal human beings' rights and freedoms. It is safe to say that the majority of constitutions worldwide embrace most -if not all- of the thirty articles in the UDHR. Among the 30 articles, article 22 addresses the right to social security, article 23 highlights an individual's right to favorable work conditions, article 24 talks about the need for reasonable limitation of work hours, and article 25 discusses an individual's right to well-being and security [3].

December 2019 saw the emergence of the novel Coronavirus Disease 2019 (COVID19), caused by the severe acute respiratory syndrome coronavirus 2 (SARS-CoV-2). It is believed to have originated in Wuhan, China. In less than a year of fighting the pandemic, frontline healthcare workers (HCWs) have faced some unprecedented challenges. As of 27th November, 2020, there have been estimated to be over 61 million cases and 1.3 million deaths due to COVID-19. ${ }^{1}$ Out of 
these, healthcare workers (HCWs) comprise over 67,569 of the cases [The median HCW infection percentage among total cases was 10.04\% (range 0-24.09\%)] [2]. The International Council of Nurses reported in May of 2020 that 90,000 healthcare workers had been infected with COVID19 [3]. Lack of adequate protective equipment was a major problem early on into the pandemic, the resource-poor countries faced the worst of such shortages. Amnesty International reported a serious shortage of Personal Protective Equipment (PPE) in nearly all of 63 Countries [4].

Possible delay in declaring the pandemic, lack of pandemic preparedness in the public health and healthcare systems in the form of clear cut guidelines and management strategies, lack of adequate training among HCWs in the face of a pandemic, and circulating conflicting evidence on the novel virus and infection were important contributing factors in causing chaos and confusion among HCWs. Across the globe, as millions of people stayed at home to minimize the risk of contracting and transmission of SARS-CoV-2, HCWs prepared to take on the pandemic head on [5]. Although HCWs have repeatedly been portrayed as "warriors in white coats", ironically, they have been expected to expose themselves to hazardous work conditions and risk of infection without being adequately provided with protective equipment. Most countries do not have strict regulations or lack implementation on work hours and workplace conditions for HCWs and lack adequate compensation, either in the form of monetary compensation or as days off to rest and recover. HCWs have been struggling to fulfill what is expected of them while neglecting their own mental and physical well-being.

We have to pause and reflect whether HCWs are able to protect their human rights, we have to question how many of them are enjoying good health themselves. As of 2020, there are 1.2 million physician HCWs in the U.S. alone [6-7]. While some countries like South Korea appeared to have handled the challenges of the pandemic better than other countries, possibly that is after having learned some valuable lessons dealing with the previous SARS and MERS pandemics, countries including the U.S. were woefully unprepared to protect HCWs amidst the rising number of COVID19 patients [8]. In India, opinions varied widely, there has also been speculation of underreporting in some places making it difficult to get a clear picture of the situation in these areas. There has also been worrisome news of the suppression of the voices of HCWs in China by their government. It is saddening to note that the rights of physicians usually overlooked are the ones stated under articles 22-25 of the UDHR, which include the right to work, the right to rest and leisure, and the right to a decent standard of living. These violations clustered together could furthermore constitute the violation of Article 4, which states the right not to be held in slavery or servitude or made to do forced labor.

\section{Human Rights and Healthcare workers}

The World Health Organization (WHO) divides workplace violence into physical and psychological with the latter including verbal abuse, threats, verbal sexual harassment, and sexual harassment [9]. Workplace violence is one of the primary infringements of human rights faced by HCWs, documented in previous literature. The situation is particularly worse in low resource settings where regulations protecting healthcare workers are sparse [10].

The prevalence of psychological violence in America, Brazil, and South Africa has been reported to be $75 \%, 39.5 \%$, and $52 \%$ respectively [11]. Similar rates can be observed in Asian and European countries. Findings depict that psychological violence was perpetrated by hospital colleagues, supervisors, patients, and relatives causing damaging psychological trauma than external violence [12]. Lack of basic health literacy has been commonly observed to be a precipitating force, exacerbating violence mainly from patients, their relatives, and attendants towards providers in the emergency department in India. Studies also show a high prevalence of violence against HCWs in developed countries [13]. Lack of fundamental rights and institutional discrimination has led to low morale, and subsequent stress, and other health concerns among HCWs. A study indicated that 1 in 5 healthcare workers in India reported experience with physical abuse consistent with prior studies [14]. Inadequate enforcement of rules governing behavior in the hospital has had an overwhelming impact on human rights violations of HCWs, which have been understudied and underreported. In May 2020, an armed attack on a hospital maternity ward in Kabul, Afghanistan, 
killed at least 24 civilians, including two infants, which was an example of a tactic of war defying international humanitarian law.

Many HCWs are overworked, underpaid, and are repeatedly exposed to psychological violence. Persistent internal violence is a known cause for depression, anxiety, insomnia, hallucinations, and even suicide [15], an example of which occurred in China [16]. Employees in health care environments are also exposed to a wide range of hazards in their work ranging from exposure to diseases, chemicals, radiation exposure, and ergonomic issues like long working hours, stressful work, and standing for long periods among other issues. The risk of infection (especially with hepatitis $\mathrm{C}$ and hepatitis B viruses) among healthcare workers (HCWs) is high as was described in a report published by the WHO, and approximately 100 health care workers die annually from occupational HIV. Almost $80 \%$ of healthcare workers remain unimmunized (against Hepatitis B) in many parts of the world. Protection of the health care workers is needed just as much as working in other hazardous environments as miners [17].

We can also find examples of human rights violations against HCWs throughout history. Throughout WW1, hospitals, hospital ships, HCWs, vehicles, and supplies of the Red Cross and Red Crescent were a target of bombing despite the presence of then valid Geneva and La Haye Conventions [18]. Similar reports emerged during Israel's attacks on the Gaza strip in 2008-2009, during which $16 \mathrm{HCWs}$ were killed and another 22 were injured while on duty. Fourteen hospitals, 38 primary health care clinics, and 29 ambulances were also destroyed or damaged during the attack [19]. Multiple reports have also emerged out of Syria. A qualitative study involving $29 \mathrm{HCWs}$ in Syria revealed that medical facilities were constantly targeted by bombs and the constant threat to doctors led to mass outward migration. Since there were physician shortages, HCWs had to act beyond their training and in very limited resources, leading to enormous pressure and psychological stress [20]. A study by Abdulaziz and others revealed that an estimated $782 \mathrm{HCWs}$ have been killed during the Syrian conflict and the deliberate targeting of healthcare facilities [21] whereas Michele et al. reported at least 157 medical personnel were executed or tortured to death [22]. A systematic review by Rubenstein et al. reported attacks on medical personnel, transport, and facilities. HCWs were attacked in El Salvador, Philippines, Sierra Leone, Bosnia, Croatia, Rwanda, Colombia, and many other countries. Human rights violations consisted of and were not limited to doctors being killed, tortured, robbed, detained, interrogated, prosecuted, and forced to withhold care to patients [23]. Female HCWs have also been a victim of added sexual harassment. An exploratory study involving 135 female HCWs in 4 different hospitals in India revealed that 77 women had experienced 128 incidents of sexual harassment, consisting of verbal and psychological harassment, sexual gestures and exposure, and unwelcomed physical contact [24].

\section{Healthcare Workers and the COVID19 Pandemic}

During the past year or so, the issues stated above have been compounded and aggravated by the complex challenges brought about by the COVID19 pandemic. The highly contagious nature of this potentially life-threatening illness mandated unprecedented changes in daily lifestyles. These changes included a compulsory suspension of most of the non-essential businesses and activities, stay-at-home orders, enforcement of social distancing rules, frequent hand-washing, and maskwearing, among many others [25]. Along with the stress and anxiety caused by the onset of an unexpected pandemic, all of these changes were particularly magnified in the lives of frontline healthcare workers, along with an array of others. Many physicians and health care practices reported great financial losses caused by COVID-19 pandemic. In one recent US-based survey, up to $97 \%$ of the surveyed medical practices suffered negatively due to the current situation [26]. Drastic decreases in revenues have been recorded in most medical practices. Furloughs, working hours cut short, and salary reductions became a looming threat for healthcare workers and adjunct paramedical personnel [27]. A recent study by the Commonwealth fund demonstrated a more than half decrease in appointments for ambulatory healthcare since the beginning of the pandemic [28] Such sudden and grave financial strain weighs heavily on many doctors' minds. They have families to support, employees and practices to keep open with little to no revenue incoming, and a considerable number of them are struggling with lingering student debt. 
Triaging in the emergency department setting was already challenging before COVID-19. Pandemic pathways were created to triage and separate the suspected COVID19 positive cases from ER care, however, there was an enormous exposure risk of HCWs in these departments, due to asymptomatic COVID19 carriers. Excluding trauma, orthopedic and emergent surgical conditions all elective surgeries were stalled or deferred creating a pool and backlog which included on-surgical malignancy surveillance screenings as well specialties with surgeries involving AGP [Aerosol Generating Procedures] like dental, ophthalmology, otorhinolaryngology has been drastically affected and triaged into prioritized cases category and deferred category [29]. There was an observed decline in immunization of young children makes them vulnerable to acquiring infections subsequently [27].

Academicians in the healthcare field faced a particularly difficult situation. The suspension of university courses in the middle of the academic year forced them to immediately adopt distance learning technologies with no prior preparation. The multiple tasks of healthcare educators have been further expanded. From digitizing all the syllabus contents to figuring out how to cope with unfamiliar online teaching methods and media sharing platforms, to devising solutions to compensate the students for the loss of the practical and didactic sessions [25]. Moreover, the research projects and the grants that have been indefinitely suspended has been a frustrating problem to many academics, this has jeopardized their ongoing researches [30]. These factors compound the stresses of overburdened academics [31].

There have been reports of HCWs experiencing extreme stress, anxiety, and depression during outbreaks and subsequently developing somatization and obsessive-compulsive disorder as a result [32]. A systematic review of the effect of COVID-19 infections on mental health concluded that there is a correlation between the SARS-CoV2 infection and worsening of mental well-being. Interestingly, it also revealed that healthcare workers are more severely affected than the lay population [33].

Apart from the risk of contracting COVID19, HCWs have been susceptible to various other health consequences during the pandemic emanating from risk factors such as long working hours, working in high-risk departments such as emergency medicine, lack of proper protection, improper infection control, prolonged PPE usage leading to skin damage, and psychological distress [34]. A recently updated article on Medscape lists about 1800 deaths of HCWs worldwide [35]. Another source listed 278 physicians' death as of April 2020 [36], with the most deaths occurring in Italy, followed by Iran and Philippines. The situations were similar during previous outbreaks such as Ebola (EVD), and MERS (Middle East Respiratory Syndrome) [37]. Nurses in many countries have suffered from various forms of assault, ostracization, and abuse. They have been pelted at, evicted from their homes, and denied access to supermarkets and to public transport [34]. A study of residents in the New York emergency department demonstrated that $97 \%$ of the residents suffered from some form of verbal violence. Interestingly, healthcare workers have come to regard psychological violence as part of their daily work [38].

A breach of human rights is seen in the restriction and penalization of free speech in many parts of the world. Doctors and nurses have been asked to remain silent about their working conditions, while there have been reports from several countries, of hospitals and clinics that have threatened HCWs with dismissal if public grievances were made on the lack of PPEs. In India, a criminal complaint was registered against a doctor who spoke on the lack of PPEs [39]. With the lack of proper training of HCWs, biosafety breaches during donning and doffing of PPEs make them vulnerable to acquiring infections.

In some communities, HCWs have experienced violence, harassment and discrimination. This has forced them to either move their homes or be physically attacked [40]. Speaking critically of some governments can bring about harsh punishment. Insecurity Insight, a non-government organization, identified 360 events in 77 countries between March 1 to April 30, 2020, ranging from protests to blocking health-care facilities, to threats and attacks on health workers in the context of COVID-19, possibly as a result of misplaced anger [41]. The World Medical Association has condemned the increasingly reported cases of HCW's being attacked. The situation in India is particularly shocking as their HCW's have been stigmatized, ostracized, discriminated against, and 
physically attacked but incidents have been reported across the world, for instance from France, Mexico, Philippines, Turkey, UK, Australia, and the US [42].

Confusion regarding the withdrawal of life-support decisions, triaging of ventilators to the needy (based on incongruent criteria) quality of end-of-life support, disruption of communication between caregiver and family resulting in disappointment with patient's unfavorable outcome, blame for an unshared decision and de-humanization of care can be contributing factors to the possible decline in the doctor-patient relationship.

As the number of COVID19 cases continues to rise, HCWs have an increased risk of exposure to SARS-CoV-2. As patient loads continue to increase, and co-workers become infected with COVID-19 the physical and psychological well-being of HCWs are taking a beating. Adding to concerns for their safety, HCWs are forced to deal with anxiety about passing the infection to their families [5]. The morbidity and mortality of HCWs have warranted interventions to curb the deleterious consequences associated with the abuse and denial of basic fundamental rights. It is pertinent to look into adequate measures and implementation of laws to curb the rising human rights violations meted out on healthcare workers.

\section{Benefits and limitations of the study}

To our knowledge, this study is the first collective work discussing human rights violations against HCWs from different countries both before and during the COVID-19 pandemic. Discussing these issues and taking action to correct them is essential to strengthening our healthcare and public health systems in order to effectively deal with the challenges that the future might have in store for us. We hope that through global co-operation and changes at the grassroots level we can make lasting improvement in these areas. There are some limitations to our study. It was not feasible to include all instances of human rights violations all over the world within the limitations of this paper. Additionally, not all instances of human rights violations against HCWs might be reported, possibly due to the reasons discussed in this paper [42].

\section{Recommendations}

Human rights violations against HCWs is an underestimated global problem that has become evident with crises [43]. The need of the hour is to prioritize the occupational health of health workers and ensure that the workforce is adequately trained and healthy by supporting those on the frontlines, all the equipment needed for their protection should be provided, more social, psychological support [44]. We recommend some ways which can be adopted by the healthcare system and governing bodies to effectively deal with the ongoing pandemic.

\section{At the Individual level}

1. Empathy training, bedside manner training, communicating bad news should be incorporated into healthcare education and training settings.

2. Healthcare workers need to be encouraged to practice self-care through practices like yoga, meditation among other health and lifestyle practices in order to maintain optimum mental and physical well-being.

\section{At the Hospital /University/Institution level}

1. Staff support measures, appropriate psychological support programs, dedicated psychological intervention teams, and availability of helplines, especially to combat the significant psychological impacts of a pandemic and high-stress work environments.

2. Establishment of shift systems, online platforms for medical assistance, incentives, provision of adequate breaks and time offs, a place to rest and sleep, and provision of mindfulness activities to support HCWs mental well-being. Additionally, establishing break time will allow for HCWs time to take care of themselves. To decrease workload by incorporating outside registered nurses into the hospital system, re-employing HCWs who recently retired, and adding medical students to the health care system in times of emergencies [7]. 
3. Training and provision on the use of personal protective equipment, strict infection control practices, and national regulatory bodies periodic checks and governmental laws to mitigate contagion and reduce the risk of infection.

4. Periodic gender and racism bias checks within a hospital and clinical settings, integrating gender into clinical audits, introducing gender sensitization training, and conventional interpersonal communication training may help reduce gender and race-based discrimination.

5. Necessary training should be provided to HCWs and medical training on technologies such as Telemedicine and using online teaching and learning platforms.

6. Adequate food and lodging facilities for HCWs in quarantine to avoid the risk of exposing their families to COVID19.

7. Adequate compensation for overtime or duty under dangerous working conditions.

At the National level

1. Formulating a Pandemic Preparedness plan based on policeman of policies aimed at increasing the capacity of health systems response (Raising the line strategy), Mitigation strategies, increasing government capacity to respond to the crisis (Strengthening strategy). ${ }^{45}$ Dedicated funds and equipment for pandemic and emergency preparedness.

2. Establishing surveillance strategies and communication lines between HCWs and governing bodies. HCWs are on the front line and possibly the first to know of the possible emergence of a healthcare emergency or if a health policy is or isn't working [4].

3. Establishing an emergency reserve medical supplies program to ensure the adequate provision, based on requirements. Such supplies may include essentials like PPEs, ventilators, masks, sanitizers among others.

4. Violence prevention programs and amendment of existing laws with strong legal repercussions for any form of psychological or physical violence on health care workers. In developing emergency care systems, a greater understanding of the surroundings and the community can help establish better practices to curb the assault of HCWs working the emergency departments.

5. Framework guidelines for addressing workplace violence in the health sector, jointly developed by WHO, ILO, ICN, and PSI, to support the development of violence prevention policies in non-emergency settings, is a tool that guides through the complexity of issues to be considered when developing anti-violence policies and strategies for all work-settings in the health sector. These can be adapted to meet local and national needs and constraints and must be utilized while creating violence prevention policies.

6. Utilization of Bioengineering expertise and modular system inventions which protects HCWs from aerosol contamination thus increasing HCWs personal safety and their confidence, especially in extensive testing in community settings.

7. Along with adequate PPE supplies that meet requirements, other practical measures including canceling non-essential events to prioritize resources, provision of food, rest, and family support needs to be considered especially when healthcare systems operate at maximum capacity.

8. Establishing grievance redressal systems for if the human rights of HCWs are to be protected from attack, government intimidation, harassment, and arrest as was described in some countries [41].

9. Public and Patient health literacy programs and awareness campaigns can help reduce the overwhelming frequency of violence emanating from patient family members and attendants precipitated by unfavorable patient outcomes or death. Studies suggest administrative measures and strong operational directives are optimal ways to control violence in health centers and therefore violence control programs should focus on administrative measures [46].

10. Pandemic and emergency preparedness training to be a part of medical training.

11. Review and implement systems to ensure implementation and quality control at the grassroot level. 


\section{At the International level}

1. Encouraging research and development of effective and affordable medicines and vaccines.

2. Global Pandemic Preparedness Plan and implementation.

3. Establishing a global alarm system for monitoring the possibility of an infectious outbreak that has the potential to become a pandemic and raising the alarm at the earliest such possibility.

4. Formulating global health policies as an example for countries to follow.

5. Global emergency health funds that could be mobilized in aid of the lower economic countries and in emergency situations. Such funds could also aid in procurement of necessary protective equipment, medicines and vaccines.

6. Treaty for global co-operation among countries, especially for emergency situations.

In the post-pandemic period, formulating and implementing a Pandemic Preparedness plan at the national, regional, and local levels would be crucial if we are to be prepared for the next seemingly inevitable one. A multipronged approach incorporating political, public health, and healthcare systems would be necessary. Public education and cooperation would also be vital in the implementation of such policies. The current pandemic has shown that strict implementation of public health measures such as physical distancing, wearing masks, and hand hygiene early in the pandemic is vital to slowing down the spread of infection.

\section{Conclusion}

Expert opinion has highlighted time and again that we could be expecting another pandemic in the future and such a situation might not be far away. The current pandemic has unearthed some painful deficiencies in the health care systems. A combined approach involving the political, public health, healthcare, and socio-economic systems would be vital if we were to be prepared for the next pandemic. In the post-pandemic period, as countries go about preparing their plans for Pandemic Preparedness it would be a good place to start by addressing the problems faced by their healthcare workers and building a strong foundation for the healthcare system. Healthcare workers are an important foundational pillar of Pandemic Preparedness. It has been clear for a long time that the healthcare systems need an upgrade centering around better working conditions for the health care workers and protection of their human rights. Global cooperation would be paramount if we are to deal with the current pandemic and minimize the potentially devastating effects of a pandemic in the future.

\section{REFERENCES}

1. Dong E, Du H, Gardner L. An interactive web-based dashboard to track COVID-19 in real-time. Lancet Infect Dis 2020;20(5):533-4.

2. Papoutsi E, Giannakoulis VG, Ntella V, Pappa S, Katsaounou P. Global burden of COVID-19 pandemic on healthcare workers. ERJ Open Res 2020;6(2).

3. Universal Declaration of Human Rights | United Nations. Accessed November 27, 2020. https://www.un.org/en/universal-declaration-human-rights/

4. Global: Health workers silenced, exposed and attacked | Amnesty International. Accessed October 25, 2020. https://www.amnesty.org/en/latest/news/2020/07/health-workers-rights-covidreport/

5. The Lancet. COVID-19: protecting health-care workers. Lancet 2020;395(10228):922.

6. Joseph B, Joseph M. The health of the healthcare workers. Indian J Occup Environ Med 2016;20(2):71-2.

7. Ehrlich H, McKenney M, Elkbuli A. Protecting our healthcare workers during the COVID-19 pandemic. Am J Emerg Med. 2020;38(7):1527-8.

8. \#Protecting \#HCWs Against \#COVID19 - and Being Prepared for Future \#Pandemics (JAMA Health Forum, summary) - ETIDIoH. Accessed October 25, 2020. https://etidioh.wordpress.com/2020/03/20/protecting-hcws-against-covid19-and-beingprepared-for-future-pandemics-jama-health-forum-summary/

$\begin{array}{llllll}\text { 9. } & (\text { No } & \text { Title) } & \text { Accessed } & \text { November } & 27,\end{array}$ 
https://www.who.int/violence_injury_prevention/violence/interpersonal/WVstresspaper.pdf

10. WHO | Violence against health workers. WHO. Published online 2018. Accessed November 27, 2020. http://www.who.int/violence injury_prevention/violence/workplace/en/

11. Behnam M, Tillotson RD, Davis SM, Hobbs GR. Violence in the Emergency Department: A national survey of emergency medicine residents and attending physicians. J Emerg Med. 2011;40(5):565-79.

12. Magnavita N, Heponiemi T. Workplace Violence Against Nursing Students and Nurses: An Italian Experience. J Nurs Scholarsh. 2011;43(2):203-10.

13. Davey K, Ravishankar V, Mehta N, et al. A qualitative study of workplace violence among healthcare providers in emergency departments in India. Int J Emerg Med 2020;13(1):33.

14. Kowalenko T, Walters BL, Khare RK, Compton S. Workplace violence: A survey of emergency physicians in the state of Michigan. Ann Emerg Med. 2005;46(2):142-7.

15. Jie L. New generations of Chinese doctors face crisis. Lancet. 2012;379(9829):1878.

16. Fang H, Wei L, Mao J, et al. Extent and risk factors of psychological violence towards physicians and Standardised Residency Training physicians: A Northern China experience. Health Qual Life Outcomes. 2020;18(1):1-11.

17. Amon JJ. Human rights protections are needed alongside PPE for health-care workers responding to COVID-19. Lancet Glob Heal. 2020;8(7):e896.

18. IMMUNE OR SOFT TARGET? THE BOMBING OF OTTOMAN HOSPITALS - PubMed. Accessed October 25, 2020. https://pubmed.ncbi.nlm.nih.gov/30727695/

19. Marton R. Human rights violations during Israel's attack on the Gaza Strip: 27 December 2008 to 19 January 2009. Glob Public Health. 2011;6(5):560-9.

20. Footer KHA, Clouse E, Rayes Di, Sahloul Z, Rubenstein LS. Qualitative accounts from Syrian health professionals regarding violations of the right to health, including the use of chemical weapons, in opposition-held Syria. BMJ Open 2018;8(8):21096.

21. Omar A. Understanding and Preventing Attacks on Health Facilities During Armed Conflict in Syria. Risk Manag Healthcare Policy 2020;13:191-203.

22. Heisler M, Baker E, McKay D. Attacks on health care in Syria - Normalizing violations of medical neutrality? N Engl J Med. 2015;373(26):2489-91.

23. Rubenstein LS, Bittle MD. Responsibility for protection of medical workers and facilities in armed conflict. Lancet. 2010;375(9711):329-40.

24. Chaudhuri P. Experiences of Sexual Harassment of Women Health Workers in Four Hospitals in Kolkata, India. Reprod Health Matters 2007;15(30):221-9.

25. Ammar N, Aly NM, Folayan MO, et al. Behavior change due to COVID-19 among dental academics - The theory of planned behavior: Stresses, worries, training, and pandemic severity. PLoS One 2020;15(9):e0239961.

26. (No Title). Accessed October 25, 2020. https://www.mgma.com/getattachment/9b8be0c2-074441bf-864f-04007d6adbd2/2004-G09621D-COVID-Financial-Impact-One-Pager-8-5x11-MW2.pdf.aspx?lang=en-US\&ext $=$.pdf

27. Rubin R. COVID-19's Crushing Effects on Medical Practices, Some of Which Might Not Survive. JAMA 2020;324(4):321-3.

28. Chatterji P, Li Y. Effects of the COVID-19 Pandemic on Outpatient Providers in the US. Natl Bur Econ Res. Published online May 18, 2020.

29. A1-Jabir A, Kerwan A, Nicola M, et al. Impact of the Coronavirus (COVID-19) pandemic on surgical practice - Part 2 (surgical prioritisation). Int J Surg. 2020;79:233-48.

30. COVID-19 and Higher Education: Today and Tomorrow.; 2020.

31. Higher Stress A SURVEY OF STRESS AND WELL-BEING AMONG STAFF IN HIGHER EDUCATION. Accessed October 25, 2020. www.ucu.org.uk

32. Ji D, Ji YJ, Duan XZ, et al. Prevalence of psychological symptoms among Ebola survivors and healthcare workers during the 2014-2015 Ebola outbreak in Sierra Leone: A cross-sectional study. Oncotarget 2017;8(8):12784-91.

33. Vindegaard N, Eriksen Benros M. COVID-19 pandemic and mental health consequences: Systematic review of the current evidence. Brain Behav Immun 2020;89:531-42.

34. Shaukat N, Ali DM, Razzak J. Physical and mental health impacts of COVID-19 on healthcare workers: A scoping review. Int J Emerg Med 2020;13(1):40-3.

35. Galbraith N, Boyda D, McFeeters D, Hassan T. The mental health of doctors during the COVID19 pandemic. BJPsych Bull. Published online 2020:1-4.

36. In Memoriam: Healthcare Workers Who Have Died of COVID-19. Accessed October 25, 2020. https://www.medscape.com/viewarticle/927976

37. Health Worker Ebola Infections in Guinea, Liberia and Sierra Leone A PRELIMINARY REPORT 
2 Health Worker Ebola Infections in Guinea, Liberia and Sierra Leone: A Preliminary Report.; 2015.

38. Schnapp $\mathrm{BH}$, Slovis $\mathrm{BH}$, Shah $\mathrm{AD}$, et al. Workplace violence and harassment against emergency medicine residents. West J Emerg Med 2016;17(5):567-73.

39. COVID-19: Restricting Health Workers' Free Speech has a Chilling Effect - Health and Human Rights Journal. Accessed November 27, 2020. https://www.hhrjournal.org/2020/05/covid-19restricting-health-workers-free-speech-has-a-chilling-effect/

40. Semple K. "Afraid to be a nurse": health workers under attack. The New York Times. April 27, 2020 https://www.nytimes.com/2020/04/27/world/americas/coronavirus-health-workersattacked.html - Google Search. Accessed October 25, 2020.

41. Amon JJ. Human rights protections are needed alongside PPE for health-care workers responding to COVID-19. Lancet Glob Health 2020;8(7):e896.

42. Vento S, Cainelli F, Vallone A. Violence Against Healthcare Workers: A Worldwide Phenomenon With Serious Consequences. Front Public Health 2020;8:570459.

43. Arnetz JE, Hamblin L, Ager J, et al. Underreporting of workplace violence: Comparison of selfreport and actual documentation of hospital incidents: Comparison of self-report and actual documentation of hospital incidents. Workplace Health Saf. 2015;63(5):200-10.

44. Ayanian John Z. JAMA Network. JAMA Health Forum; 1 Apr. 2020. Mental Health Needs of Health Care Workers Providing Frontline COVID-19 Care.

45. Peña S, Cuadrado C, Rivera-Aguirre A, et al. PoliMap: A taxonomy proposal for mapping and understanding the global policy response to COVID-19. Published online 2020. doi:10.31219/osf.io/h6mvs

46. Lin L-Y, Juan C-W, Chu C. The needs and potential solutions for improvement of workplace violence management in emergency departments in Taiwanese hospitals. J Acute Med 2014;4(1):13-9.

Acknowledgements: Nil

Funding: Nil

Conflict of interest: Nil 